\title{
¿Alimentos retroactivos o daños? Mecanismos para rectificar los efectos de una sentencia injusta
}

\author{
Hugo Cárdenas Villarreal* \\ Bárbara Sepúlveda San Martín**
}

\begin{abstract}
RESUMEN
El siguiente artículo estudia los efectos del incumplimiento del deber de transparencia patrimonial contenido en el artículo $5^{\circ}$ inciso primero de la Ley $N^{\circ} 14.908$, lo que provoca la dictación de una sentencia de alimentos injusta. Se sostiene que, ante esta situación, el alimentario presenta a su disposición, además de la acción para corregir el monto de las pensiones alimenticias a futuro, una acción para resarcir el monto de las pensiones alimenticias defraudadas junto con la consecuente indemnización por daños extrapatrimoniales que se puedan vincular con su defraudación.
\end{abstract}

Transparencia patrimonial - alimentos - responsabilidad civil

\section{Retroactive maintenance or damages? \\ Mechanisms to rectify the effects of an unfair judgement}

\begin{abstract}
The following article analyses the effects of the breach of the obligation of the non custodial parent to reveal in court and under oath his assets, duty contained in article 5 of the chilean family act $N^{\circ} 14.908$, and the unfairness that causes this breach in the issuance of judicial judgment. It is argued that, in this situation, the custodial parent has a legal action available to correct the amount of child support and cause for suit to compensate the lesser amount of child support paid by the non custodial parent, through non-pecuniary damages".
\end{abstract}

Obligation to reveal - child support - non contractual damages

\footnotetext{
* Licenciado en Derecho, Universidad Complutense de Madrid, España. Doctor en Derecho, Pontificia Universidad Católica de Chile. Profesor de Derecho Civil, Universidad de Chile. Correo electrónico: hcardenas@derecho.uchile.cl

** Licenciada en Ciencias Jurídicas y Sociales, Universidad de Chile. Correo electrónico: barbarasepulvedasm@gmail.com

Artículo recibido el 15.8.2019 y aceptado para su publicación el 10.1.2020.
} 


\section{INTRODUCCIÓN}

$\mathrm{D}$ e todas las acciones que conocen los Tribunales de Familia, aquellas que buscan la fijación de alimentos son las más numerosas ${ }^{1}$. Lamentablemente, en la práctica, existe la percepción de que la suma que se obtiene en dichos juicios es insuficiente para satisfacer las necesidades de los alimentarios, y menor a la que corresponde a la situación económica del demandado ${ }^{2}$. Ello se debe, entre otras razones, a la dificultad probatoria que enfrenta el alimentario al tener que demostrar la efectiva capacidad patrimonial del alimentante.

Es cierto que el ordenamiento jurídico le da al alimentario vías para proteger sus intereses cuando el alimentante esconde o se desprende de sus bienes como, por ejemplo, la acción pauliana especial contenida en el artículo $5^{\circ}$ inciso $7^{\circ}$ de la Ley $\mathrm{N}^{\circ} 14.908$ sobre Abandono de Familia y Pago de Pensiones Alimenticias. Sin embargo, la falta de una información veraz y completa respecto del patrimonio del alimentante normalmente tiene como resultado una sentencia injusta, al no permitirle activar las diversas vías que contempla el ordenamiento para proteger sus intereses.

Ante tal eventualidad, y firme la sentencia de alimentos, el ordenamiento jurídico chileno no contempla ningún recurso procesal que permita corregir dicha sentencia. La solución que se pone a disposición de los alimentarios defraudados es la posibilidad de pedir que se adecuen los alimentos (cosa juzgada formal). Pero esta vía solo tendrá efectos hacia el futuro y, por lo mismo, la diferencia entre los alimentos que se fijaron y los que se debieron haber fijado durante el tiempo que tarda en descubrirse el engaño, simplemente la pierde el alimentario.

En el contexto descrito, el presente trabajo tiene como objetivo explorar una vía de acción que permita suprimir los efectos perniciosos de una sentencia de alimentos injusta ${ }^{3}$, más allá de la posibilidad de aumentar la pensión alimenticia, cuando se descubra la verdadera capacidad patrimonial del alimentante. Defenderemos como tesis que el alimentario dispone -además de una acción para adecuar la pensión alimenticia hacia el futuro- de una acción para recuperar los alimentos defraudados, así como para que se le indemnicen todos los otros perjuicios que se puedan vincular causalmente con esa defraudación.

Estructuralmente, este trabajo se encuentra dividido en dos partes: en la primera se analiza el contenido y el alcance del deber de transparencia patrimonial; y en la segunda se analizará la eficiencia de la acción de aumento de alimentos en orden a eliminar los efectos de una sentencia injustamente emitida, así como la viabilidad de una acción de

\footnotetext{
${ }^{1}$ Según los últimos informes del Instituto Nacional de Estadística (INE), el promedio anual de ingreso en materias de alimentos fue de 200.000 causas, lo que corresponde aproximadamente al $25 \%$ del total ante los tribunales de familia. INE, 2015, 2016 y 2017.

${ }^{2}$ Valenzuela, 2019.

${ }^{3}$ Se hace presente que el objetivo de este trabajo es abordar exclusivamente los efectos de la sentencia definitiva de alimentos y no los alimentos provisorios.
} 
perjuicios que persiga la reparación integral de todos los daños que se puedan vincular con la referida sentencia.

\section{Contenido y ALCANCE DEL DEBER de TRANSPARENCIA PATRIMONIAL}

El que en adelante llamaremos deber de transparencia patrimonial ${ }^{4}$ se encuentra consignado en el numeral $1^{\circ}$ del artículo $5^{\circ}$ de la Ley $\mathrm{N}^{\circ} 14.908$ en los siguientes términos:

“El juez, al proveer la demanda, ordenará que el demandado acompañe, en la audiencia preparatoria, las liquidaciones de sueldo, copia de la declaración de impuesto a la renta del año precedente y de las boletas de honorarios emitidas durante el año en curso y demás antecedentes que sirvan para determinar su patrimonio y capacidad económica. En el evento de que no disponga de tales documentos, acompañará, o extenderá en la propia audiencia, una declaración jurada, en la cual dejará constancia de su patrimonio y capacidad económica. La declaración de patrimonio deberá señalar el monto aproximado de sus ingresos ordinarios y extraordinarios, individualizando lo más completamente posible, si los tuviere, sus activos, tales como bienes inmuebles, vehículos, valores, derechos en comunidades o sociedades".

La interpretación de esta norma no ha sido uniforme en la más bien escasa doctrina que se ha ocupado de ella. Algunos autores han sostenido que se trata de una presunción legal $^{5}$, por medio de ella se presumirá cierta la capacidad económica del alimentante considerada en la demanda por el demandante/alimentario. Otros han visto en la norma una manifestación de la teoría de las cargas dinámicas de la prueba ${ }^{6}$, en tanto que la misma se trasladaría del demandante al demandado. Un tercer grupo de autores simplemente la consideran una obligación de naturaleza procesal ${ }^{7}$. Dentro de este último grupo, Meneses ha señalado que la norma contiene un deber de esclarecimiento de los hechos que recaería sobre el demandado ${ }^{8}$.

${ }^{4}$ Según Pérez Ragone y Silva Álvarez, la norma referida constituye la principal y más decidida novedad en materia de transparencia patrimonial desde la perspectiva procesal. PÉrEZ y SiLVA, 2009, pp. 111 y 112.

${ }^{5}$ LePIN le da continuidad al criterio rector de la historia de la Ley $\mathrm{N}^{\circ} 20.152$, en la que los parlamentarios pretendían lograr que los hechos relativos a la capacidad patrimonial del alimentante, contenidos en la demanda deducida por el alimentario, fuesen presumidos como ciertos. LePIN, 2014, pp. 6-7. Por su parte, BARRIENTOS, 2015, p. 681, afirma que la carga de la prueba en lo tocante a las facultades del deudor y sus circunstancias domésticas pesa sobre el mismo deudor.

${ }^{6}$ GonZÁLEZ, 2012, pp. 379-383 y GonZÁlez, 2013 p. 145.

${ }^{7}$ NúÑEZ Y CORTÉs, 2012, pp. 455-459.

${ }^{8}$ Meneses, 2008, pp. 226-227 y 239-240. Según el autor, el eje principal de la reforma de la Ley $\mathrm{N}^{\circ} 20.152$ ha sido la llamada "tutela judicial efectiva", que entre sus variantes de aplicación en el proceso exige que los litigantes realicen las actividades necesarias para que el sentenciador alcance el conocimiento pleno acerca de los hechos relevantes del juicio. En un proceso de alimentos, se traduce en la legítima expectativa tanto del juez como del alimentario de conocer la capacidad patrimonial del alimentante, de forma 
En nuestra opinión la norma contenida en el artículo 5 inciso $1^{\circ}$ puede ser entendida como una obligación legal que tiene varios destinatarios: en primer lugar, obliga al juez a ordenar al demandado que acompañe elementos que le permitan identificar la entidad de su patrimonio; y, en segundo lugar, obliga al demandado a cumplir con la orden acompañando la referida documentación o emitiendo una declaración jurada, en caso de no disponer de los documentos necesarios para estos efectos. En consecuencia, al equiparar el acto de acompañar los documentos con el acto de emitir una declaración jurada, es posible concluir que la norma contempla una obligación de información. Específicamente, obliga al alimentante a aportar información veraz que permita conocer su situación patrimonial.

Los autores que ven en la norma una presunción contra el alimentante demandado parecen razonar acerca de la idea de que, si no aporta elementos de juicio tendientes a develar su capacidad patrimonial, se tendrá por cierto lo que se afirma en la demanda respecto de la misma, así como se propuso en la discusión parlamentaria de la Ley No 20.152. Sin embargo, de la simple lectura del artículo 5 inciso $1^{\circ}$ de la Ley $\mathrm{N}^{\circ} 14.908$, es posible desprender que la norma no conmina al demandado a probar su situación patrimonial bajo sanción de tener por acreditados los hechos indicados en la demanda en el juicio de alimentos, como ocurriría si se tratara efectivamente de una presunción como la que se propuso en la discusión parlamentaria referida. Así, no se observa sustento razonable para inclinarse por esta interpretación?.

Tampoco es posible aceptar que se trate de una manifestación de la doctrina de las cargas probatorias dinámicas en tanto que la forma de operar de cualquier versión de dicha teoría produce una alteración del onus probandi, y ese efecto no se observa en esta hipótesis ${ }^{10}$. Lo anterior porque, como ya señalamos, el demandado satisface su obligación simplemente aportando documentos o acompañando una declaración jurada, y el incumplimiento de esta obligación no trae aparejado como resultado la acreditación de ningún hecho. A mayor abundamiento, una vez aportados los documentos referidos o la declaración jurada, será carga del demandante diligente ofrecerlos en la audiencia preparatoria e incorporarlo posteriormente en la audiencia de juicio, como prueba documental, o utilizarlos como prueba sobre prueba ${ }^{11}$.

Por todo lo anterior, sencillamente estamos ante una obligación legal cuya infracción acarrea importantes consecuencias civiles y penales, según lo dispone la misma

tal que su configuración normativa excede con creces el clásico principio dispositivo procesal, en la fórmula de cargas probatorias u alteración del onus probandi.

${ }^{9}$ GOLDSCHMIDT, quien colaboró con la doctrina procesal introduciendo el concepto de cargas procesales, indica que en los procedimientos donde impera el principio inquisitivo y corresponde al juez ser partícipe del descubrimiento de la verdad, no existen cargas sino deberes, sosteniendo: La obligación de comparecer en los procesos sobre matrimonio y estado familiar, que están dominados por el principio inquisitivo, afecta a las partes como medio de prueba, y también en ellos puede ser decretada la conducción ante el Tribunal. GoldSCHMIDT, 1936, p. 202.

${ }^{10}$ Una posición muy crítica de la teoría de las cargas probatorias dinámicas puede verse en NiEva et al., 2019, pp. 53 y ss.

11 Alvear, 2015, p. 40. 
norma $\left(c f r \text {. incisos } 4^{\circ}, 5^{\circ}, 6^{\circ} \text { y } 7^{\circ}\right)^{12}$. Se trataría, en definitiva, de un mandato de orden público $^{13}$ que entendido desde el principio de buena fe procesal ${ }^{14}$, tiene por objeto proteger al alimentario obligando al demandado alimentante a aportar los documentos necesarios (o jurar) para esclarecer su situación patrimonial ${ }^{15}$.

No obstante que el tema que aquí se trata ha sido poco abordado por la jurisprudencia de los tribunales, comienzan a verse algunos pronunciamientos al respecto. Así, la Corte de Apelaciones de Chillán ha sostenido que la prueba de las facultades económicas del alimentante/demandado:

“ $[\mathrm{L}] \mathrm{e}$ concierne a él, considerando especialmente lo dispuesto en el artículo $5^{\circ}$ de la Ley $\mathrm{N}^{0} 14.908$ en virtud del cual el juez, al proveer la demanda, debe ordenar al demandado, acompañar, en la audiencia preparatoria, todos los antecedentes que sirvan para determinar tanto su patrimonio cuanto su capacidad económica, por lo que es el demandado quien tiene la obligación procesal de agregar toda la documentación que permita visualizar sus facultades económicas y circunstancias domésticas y cuyo incumplimiento doloso, incluso, puede acarrearle sanciones penales; todo lo cual, por cierto, podrá impugnar, el demandante" ${ }^{16}$.

Con independencia de la calificación teórica ${ }^{17}$, es claro que para esta jurisprudencia se trata de una norma que, prima facie, compele al alimentante a aportar información que sacrificará el interés propio en beneficio del interés del alimentario. La excepción al principio de que nadie está obligado a actuar contra su propio interés que contiene esta norma ${ }^{18}$, tiene como fundamento la especialidad de los procedimientos de familia. En efecto, existe acuerdo respecto de que, en aquellos procedimientos como los de familia en los que el litigio versa acerca de derechos indisponibles o prima un interés general, el principio de buena fe actúa morigerando la supremacía del principio dispositivo ${ }^{19}$. Desde otra perspectiva, se puede decir que desde el orden público familiar son positivamente valoradas las normas que obligan a una de las partes a aportar información, no obstante que ello pueda afectar su interés individual ${ }^{20}$.

Sin perjuicio de lo anterior, debido al objetivo que guía este trabajo, lo que importa es determinar, en los términos más concretos posibles, cuándo y cómo se transgrede la

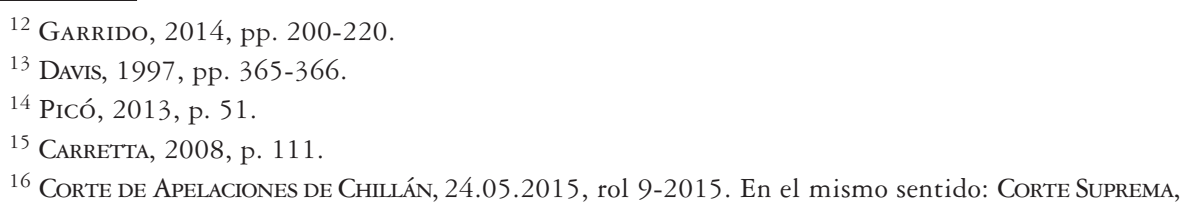
15.12.2014, rol 18924-2014.

${ }^{17}$ Respecto de la distinción entre obligaciones procesales y deberes, y acerca de la distinción de sus efectos puede verse: CARretTa, 2008, pp. 101 y ss.

${ }^{18}$ Una crítica a la introducción de deberes basados en la buena fe procesal en el procedimeitno civil puede verse en: HunTER, 2008, pp. 165-167.

${ }^{19}$ De los deberes de colaboración puede verse en la doctrina nacional: AguirrézABAL, 2015, p. 306.

${ }^{20}$ Hunter, 2007, pp. 213 y ss. 
norma de referencia. En el contexto que venimos describiendo, nos parece que dos son las conductas que deben ser realizadas, si no se quiere transgredir el deber de transparencia patrimonial.

\section{Transgresión al deber de transparencia patrimonial I: incumplimiento del deber de veracidad $y$ completitud}

La primera de las conductas que debe realizar el demandado es cumplir con el deber de veracidad y completitud. En efecto, la obligación de transparencia patrimonial contenida en el artículo $5^{\circ}$ inciso $1^{\circ}$ de la Ley $\mathrm{N}^{\circ} 14.908$ obliga al alimentante demandado a mostrar toda su capacidad económica ${ }^{21}$. Por tanto, no solo impone el deber de no mentir sino la conducta activa de decir toda la verdad ${ }^{22}$.

La oportunidad para cumplir con este deber es la audiencia preparatoria ${ }^{23}$. El alimentante debe concurrir a la audiencia y aportar los documentos o hacer la declaración jurada, si no quiere sufrir las sanciones conminatorias de los incisos $2^{\circ}, 4^{\circ}, 5^{\circ}, 6^{\circ}$ y $7^{\circ}$ del propio artículo 5 de la Ley $\mathrm{N}^{0} 14.908^{24}$.

Cualquier forma de contravención del deber de veracidad y completitud podría tener un reflejo negativo (generar un yerro) en la determinación del quantum de los alimentos. Y si de ese yerro resulta en una resolución no ajustada a lo que en derecho corresponde, la acción puede ser constitutiva de un fraude ${ }^{25}$ o de una estafa procesal ${ }^{26}$.

Como la obligación de transparencia patrimonial del deudor tiene consecuencias probatorias para la parte contraria como para el juez ${ }^{27}$, su efecto alcanza tanto a los equivalentes jurisdiccionales (conciliación o la transacción) como a la sentencia definitiva,

${ }^{21}$ También se ha discutido el alcance de esta obligación de transparencia. Así, según NúÑEZ y CorTÉs, basta con que el demandado acredite su activo y, aunque nada impide que muestre el pasivo, ha de tenerse presente que esta posibilidad no está contenida en la norma. NúÑEZ y CoRTés, 20 I 2, P. 456. Nosotros creemos que sí se encuentra contemplado en la norma, ya que el demandado debe acreditar completamente su patrimonio y capacidad económica. Como se sabe, la existencia de pasivo es un buen indicador del activo y la capacidad crediticia de las personas. Así como ha señalado la jurisprudencia: (... f la circunstancia que un demandado de alimentos acredite la existencia de deudas bancarias solo prueba su capacidad de crédito, y no una mala situación económica (...). Corte de Apelaciones de La Serena, 12.08.2015, rol 111-2015.

22 Gorigoitía, 2008, pp. 151-153.

${ }^{23}$ Su omisión por parte del juez permite a la parte afectada interponer recurso de casación: Corte de Apelaciones de Concepción, 08.09.2011, rol 444-2011.

${ }^{24} \mathrm{El}$ requerimiento que puede hacer el juez en la audiencia preparatoria respecto del cumplimiento de esta obligación de aclaración del patrimonio, responde a la facultad directiva, privativa y discrecional que posee este en la audiencia. En este sentido, resolviendo de un Recurso de Amparo, la Corte de Valparaíso sostuvo: (...) que en uso de las facultades que la ley le confiere al juez de esta causa, éste, dirigiendo la audiencia, advirtió a los demandados sobre las posibles consecuencias de su incumplimiento -que se encuentran contenidas en la ley-y de las medidas que podría adoptar. Corte de Apelaciones de Valparaíso, 08.09.2011, rol 247-2015. Véase también: SÁNCHEZ, 2019, pp. 53-64.

${ }^{25}$ Ferrer, 1966, pp. 5-11.

26 Hernández, 2010, pp. 215-218.

${ }^{27}$ Condorelli, 1986, pp. 205-206. 
provocando así la consumación de la estafa procesal ${ }^{28}$. Frente a ello, la lógica procesal civil lleva a pensar que la parte afectada se encontraría legitimada para interponer un recurso de revisión ante la Corte Suprema, según lo dispone los numerales $1^{\circ}$ y $3^{\circ}$ del artículo 810 del Código de Procedimiento Civil con el apoyo de parte de la doctrina ${ }^{29}$. No obstante lo anterior, la Corte Suprema ha rechazado recursos de revisión en contra de las sentencias que fijan alimentos, en atención al carácter esencialmente modificable (cosa juzgada formal) que poseen estas sentencias ${ }^{30}$.

Al hacer referencia al carácter esencialmente modificable de la sentencia de alimentos, la Corte Suprema parece avalar la tesis de que la vía idónea para solventar los efectos de una sentencia injusta es el juicio de adecuación. Como veremos un poco más adelante, esta solución resuelve una parte del problema, pero no es suficiente para dejar indemne al alimentario.

\section{Transgresión al deber de transparencia patrimonial II: incumplimiento del deber de coberencia}

La segunda de las conductas que debe realizar el alimentante demandado es mantener la integridad del patrimonio declarado, es decir, cumplir con el deber de coherencia. Y es que, para que la norma que impone el deber de transparencia patrimonial sea eficaz, debe entenderse implícito un efecto normativo que vinculará al alimentante durante todo el procedimiento: no deberá realizar actos que disminuyan sensiblemente el patrimonio declarado. De esta manera, avanzamos desde un deber de veracidad y completitud, a un deber de acción coherente con la declaración patrimonial ${ }^{31}$. El fundamento último de este nuevo deber, es la protección de la confianza depositada en el alimentante por el sistema jurídico ${ }^{32}$.

Así las cosas, por medio del referido deber, la obligación de transparencia patrimonial tendrá una importante repercusión en la etapa de juicio que va entre la audiencia preparatoria y la dictación del fallo, así como en la etapa de cumplimiento de los alimentos.

Con posterioridad a la audiencia preparatoria del juicio de alimentos, el incumplimiento de la obligación del alimentante en relación con su deber de transparencia patrimonial puede presentar múltiples formas en virtud del deber de coherencia. Así, por ejemplo, puede ocurrir que en el período de cumplimiento de los alimentos el

${ }^{28}$ Durante la tramitación del proyecto de Ley $N^{0} 20.152$ se refirió como un hecho habitual que los alimentantes contumaces evaden el pago de sus obligaciones por medios fraudulentos, tales como esconder bienes, negar ingresos y otros artificios, como fraude y simulación. Finalmente, en la tramitación del proyecto se deshechó la creación de tipos penales nuevos en atención a que la conducta ya se encuentra penada en forma general, y a la dificultad probatoria de los elementos subjetivos del tipo y, sobre todo, porque la tipificación de estas conductas haría que los tribunales de familia debiesen inhibirse de seguir conociendo esta materia, derivando el problema al sistema penal.

\footnotetext{
${ }^{29}$ Maturana y Mosquera, 2010, p. 575.

${ }^{30}$ Corte Suprema, 10.08.2011, rol 7322-2011.

31 Carretta, 2008, p. 123.

32 Padilla, 2013, pp. 138-144.
} 
deudor enajena bienes y le ocasiona un perjuicio al alimentario pues se encontrará en la imposibilidad de presentar bienes sobre los cuales dirigir la acción ejecutiva o el cumplimiento incidental ${ }^{33}$. Otra forma de infracción al deber de coherencia puede ocurrir en el período que va entre la audiencia preparatoria y la sentencia. A modo ilustrativo, el juez podría otorgar a favor del alimentario un usufructo de un bien raíz declarado por el alimentante, pero este puede enajenarlo con anterioridad a la dictación de la sentencia definitiva, haciendo que esta se torne absolutamente inoficiosa ${ }^{34}$.

Para solucionar los supuestos descritos, el legislador incorporó una acción pauliana especial que contempla, entre otras ventajas respecto de su análoga civil, una presunción de mala fe tanto del alimentante como del tercer adquiriente. Sin embargo, y no obstante su innegable utilidad, estas herramientas no serán suficientes para reparar todas las consecuencias de las conductas defraudatorias que se pueden verificar.

\section{Algunas vías de solución para los efectos de una SENTENCIA DE ALIMENTOS INJUSTA}

Ya hemos visto que la Corte Suprema estima que no cabe recurso de revisión en contra de la sentencia que fija los alimentos. Por lo mismo, corresponde explorar otras vías para rectificar los efectos patrimoniales de una sentencia firme que, en el mejor de los casos, debe ser calificada como defectuosa.

\section{La acción para aumentar los alimentos: una solución insuficiente}

En caso de que el alimentario descubra que la situación patrimonial del alimentante que se tuvo a la vista al momento de fijar los alimentos (ya sea por sentencia o por acuerdo judicial) no guardaba relación con la realidad, es admisible preguntarse por las condiciones que se deben dar para que proceda la acción de adecuación de los alimentos en atención a esa realidad que ahora se descubre. La pregunta interesa porque el juicio de adecuación requiere un cambio en las circunstancias económicas del alimentante (o en las necesidades del alimentario) y, en el caso que tratamos, no existe propiamente hablando una modificación de las circunstancias del alimentante. Se trata más bien de que, en el primer juicio, la decisión se fundó en una falsa representación de sus circunastancias económicas.

Al respecto, el artículo 332 del Código Civil establece que (l)os alimentos que se deben por ley se entienden concedidos para toda la vida del alimentario, continuando las circunstancias que legitimaron la demanda. Según la doctrina que se ha referido a esta disposición, siempre que se produzca una modificación de las circunstancias económicas de las partes de una relación de alimentos, se podrá pedir la modificación de la pensión de alimentos ${ }^{35}$.

\footnotetext{
33 Pérez y Silva, 2015, pp. 111-112.

34 Caso paradigmático: Tribunal de Familia de Ovalle, 18.04.2011, rol C-631-2010; revocada por Corte de Apelaciones de La Serena, 05.08.2011, rol 63-2011.

35 Ramos, 2010, pp. 558-559.
} 
Pensamos que la solución es la misma, tanto si efectivamente se produce una variación en las circunstancias económicas del alimentante; como si se descubre que las circunstancias económicas que se tuvieron a la vista no se correspondían con la realidad. La socialización del proceso de alimentos ${ }^{36}$ y la introducción del deber de esclarecimiento patrimonial, que importa los deberes de veracidad, completitud y coherencia, impiden admitir la divergencia en el proceso de alimentos entre una verdad material y una formal ${ }^{37}$.

Una posición negativa respecto de la posibilidad de adecuar los alimentos implicaría cargar al alimentario con todos los costos de la falta de información en un proceso en que, según la ley, el deber de aportar dicha información recae, de manera importante, en el alimentante. Por lo demás, en tanto materia de orden público, no puede avalarse una interpretación del derecho y del proceso (social y ya no garantista) ${ }^{38}$, que implique una renuncia de alimentos futuros por el alimentario al momento de mediar, transigir o conciliar.

Al respecto, resulta esclarecedor un fallo de la Corte Suprema que confirmando lo sentenciado por la Corte de Apelaciones de Concepción, razona acerca de la idea de que para ejercer la acción de aumento de alimentos existiría otra causal distinta a la variación de las circunstancias económicas, esto es, el ocultamiento de patrimonio en el primer juicio de alimentos y que debe hacerse valer como punto de prueba. En lo que aquí interesa, la Corte Suprema sostuvo:

"Que, [...] el punto central propuesto en la demanda es la obtención del aumento de los alimentos fijados, no en función de un cambio de circunstancias, sino que, justificado por la falta de investigación del patrimonio del demandado, [... Indica que los sentenciadores, no obstante aquello, fallaron considerando como causa de pedir la variación de las circunstancias de las partes, lo que no fue el objeto del juicio, infringiendo las normas señaladas" 39 .

Por todo lo anterior, se puede sostener que procederá la acción de aumento de alimentos si se demuestra que hay una diferencia entre el patrimonio declarado en el primer juicio y el actual, con independencia de la razón por la que se produce esa diferencia.

No obstante lo anterior, puede considerarse que la acción para aumentar los alimentos es una solución útil, pero no completa. Ello, en tanto que si bien se trata de una acción que servirá para corregir el defecto de la sentencia de alimentos hacia el futuro, no es una solución para la defraudación que ha operado en el tiempo que media entre la fecha en que se dictó la sentencia injusta y la fecha que se dicte la sentencia que aumente los alimentos.

\footnotetext{
${ }^{36}$ Montero, 2006, pp. 294-356.

37 Gorigoitía, 2008, p. 152.

38 Montero, 2006, pp. 294-356.

${ }^{39}$ Corte Suprema, 16.08.2016, rol 44994-2016, el que confirma sentencia de: Corte de Apelaciones de Concepción, 30.06.2016, rol 297-2016.
} 


\section{La acción de daños entre familiares: un complemento necesario}

El ámbito del derecho familiar es uno de los últimos reductos donde se ha discutido utilidad y aplicabilidad del instituto de la responsabilidad civil. Se ha observado que el resarcimiento de daños en el ámbito familiar ha sido la síntesis de una larga y compleja evolución de una multiplicidad de factores condicionantes de indole jurídica, sociológica, cultural e ideológica ${ }^{40}$. Por esta razón, la recepción de esta idea exhibe en el derecho comparado un desarrollo un tanto dispar ${ }^{41}$.

Tan solo por citar algunos ejemplos, en países como España o Italia, se ha explicado el fenómeno referido apelando a una transformación de lo que entendemos por familia y a una revaloración de la idea de persona ${ }^{42}$. En esta nueva comprensión, la familia se ve como una estructura al servicio del desarrollo y protección de los derechos del individuo ${ }^{43}$. En el derecho francés, que contempla un régimen especial para los daños con ocasión del divorcio, se debate intensamente si se aplica el régimen general del Código Civil o el régimen especial cuando se producen daños durante el matrimonio ${ }^{44}$. Por su parte, en países de nuestro entorno cultural como Uruguay $^{45}$ y Argentina ${ }^{46}$, la existencia de un vínculo familiar no ha impedido el desarrollo de la acción de perjuicios entre familiares.

En Chile, el debate se ha reproducido con gran intensidad en los últimos años y, salvo la indemnización por incumplimiento de deberes conyugales ${ }^{47}$, se observa una tendencia en la doctrina contemporánea a aceptar la aplicación del derecho de daños en el ámbito de la familia ${ }^{48}$. En la jurisprudencia, algunos fallos se han mostrado proclives a aceptar la aplicación de la responsabilidad entre familiares, no obstante que a la fecha son muy pocos los casos en los que efectivamente se ha obtenido una condena ${ }^{49}$.

${ }^{40}$ ViVANCO, 2018, pp. 13-14.

${ }^{41}$ Un muy buen análisis de los diferentes supuestos que se indemnizan en VivanCO, 2018, pp. 181 y ss.

${ }^{42}$ En el derecho español puede verse a: Roca, 1999, p. 86; MARTín-CaSAls y Ribot, 2011, pp. 544545 y en el derecho italiano puede verse: PATTi, 1984, p. 32.

43 Roca, 2000, p. 540.

44 TAPIA, 2018, pp. 89-115.

45 HOWARD, 2016, pp. 171-173.

46 Medina, 2015, p. 21; TAnZi y Papillú, 2011, pp. 150-153; Dutto, 2007, pp. 35-36; Ferrer I RiBA, 2001, pp. 16-17.

47 A favor de la indemnización de los daños en el ámbito familiar, incluso entre cónyuges: VARGAS, 2015 , p. 81, De la tendencia general a aceptar la utilización del derecho de daños en el ámbito de familia con exclusión de los deberes conyugales: Hernández, 2016, pp. 96 y ss.; y TAPiA, 2018, pp. 69-70. Un análisis de la jurisprudencia en materia de responsabilidad civil entre cónyuges en VARAs, 2016, pp. 248 y ss.; y Turner, 2017, pp. 557-665.

${ }^{48}$ Un análisis de la discusión y de los supuestos de responsabilidad civil entre familiares más allá de los deberes conyugales en Lepin, 2017, p. 507; una completa monografía de la responsabilidad civil entre familiares en Vivanco, 2019; un completo análisis de los argumentos que excluyen la responsabilidad civil y su superación en el ámbito familiar en Álvarez, 2019, pp. 37 y ss.

${ }^{49}$ Hasta la fecha solo tenemos concocimiento de que se ha acojido una acción de perjuicios entre familiares en un caso de violencia intrafamiliar entre cónyuges: Corte Suprema, 30.12.2014, rol 10622-2014. En otro tipo de casos como, por ejemplo, el contagio de enfermedades de transmisión sexual, la jurisprudencia 
Aunque no podemos detenernos a revisar cada uno de los argumentos que se han opuesto a la utilización de la institución de la responsabilidad en el ámbito de la familia, nos parece que, en términos generales (con exclusión de los deberes conyugales), su utilización se justifica a base de dos grandes razones que dicen relación con: i) operación del principio de igualdad en la relaciones de familia; y ii) con el hecho de que la legislación positiva chilena regula hipótesis de daños entre familiares.

Respecto de la primera razón, la idea de relaciones de igualdad entre los miembros de la familia y la valoración de los derechos fundamentales de sus integrantes por sobre el interés familiar, posibilita en términos conceptuales la operación del principio alterum non laedere. La perspectiva de la igualdad entre familiares excluye los argumentos que historicamente se utilizaron para evitar la aplicación del derecho de daños en este ámbito, como la inmunidad familiar o la estabilidad y paz dentro de la familia ${ }^{50}$.

Respecto de la segunda razón referida, el hecho de que el derecho positivo cada vez regule más hipótesis de indemnizaciones entre familiares, es un argumento que apoya la posición que sostiene la existencia de un principio general de aplicación de la acción de daños. Entre los supuestos que se encuentran regulados de manera explícita en la legislación positiva, encontramos: i) la responsabilidad del padre o madre que administra los bienes del hijo (artículo 256 del Código Civil); ii) la responsabilidad civil por hurtos entre parientes contemplado en el artículo 489 del Código Penal; y iii) la responsabilidad por daños regulada en el artículo 11 de la Ley $\mathrm{N}^{\circ} 20.066$ sobre violencia intrafamiliar. Nos parece que las razones expuestas impiden excluir, en términos generales, la aplicación del derecho de daños en el ordenamiento jurídico chileno. Por lo mismo, corresponde ahora analizar si, a la luz de las características propias de la obligación alimenticia, podemos agregar nuevas razones justificativas.

\section{2.a) Responsabilidad civil por incumplimiento de la obligación alimenticia}

En nuestro medio la obligación alimentaria esta recogida positivamente en el artículo 323 del Código Civil, y ha sido definida doctrinariamente como aquella por la que una persona debe proporcionar a otra (lo\} que necesite para subsistir de un modo correspondiente a su posición social y que debe cubrir, a lo menos, el sustento, la babitación, vestidos, salud, movilización, enseñanza básica y media, aprendizaje de alguna profesión u oficio ${ }^{51}$. Como se desprende de la definición, se trata de una obligación que tiene un indiscutible contenido patrimonial y, por lo mismo, todas las objeciones a la aplicación del derecho de daños que se basan en la concepción ética de los deberes de familia, difícilmente pueden ser atendidas respecto del incumplimiento de esta obligación. Por el contrario, su carácter

se ha mostrado proclive a aplicar el instituto de la responsabilidad civil en el ámbito familiar, aunque en el caso concreto se haya rechazado la demanda porque no se pudo probar alguno de los requisitos de la responsabilidad: Corte de Apelaciones de Talca, 30.08.2012, rol 133-2012. Una relación de los distintos fallos que han abardado la materia puede verse en TAPIA, 2018, pp. 29-49.

\footnotetext{
${ }^{50}$ LePIN, 2014, p. 437.

51 Ramos, 2010, p. 543.
} 
patrimonial permite que se pueda cuantificar y ejecutar en el patrimonio del deudor, sin que se afecte significativamente la libertad personal del mismo ${ }^{52}$.

Aparte de lo referido, y de algún apoyo doctrinal indirecto ${ }^{53}$, otras razones que sirven para fundamentar las indemnizaciones por la transgresión de esta obligación dicen relación con: i) el carácter de derecho fundamental que revisten los alimentos; ii) el hecho de que el Código Civil regula una hipótesis de daños respecto de los alimentos en el artículo 328; iii) el hecho de que no solo se deben alimentos entre familiares; y iv) el hecho de que los daños derivados del incumplimiento de esta obligación son indemnizados en ordenamientos similares al nuestro.

Respecto del carácter fundamental del derecho se puede afirmar, pese a que la Constitución no lo consagra en términos explícitos, que el derecho de alimentos debe entenderse incorporado al bloque de constitucionalidad desde que ha sido consagrado en Convenciones Internacionales suscritas y ratificadas por Chile ${ }^{54}$. En lo que aquí interesa, el carácter fundamental del derecho de alimentos fuerza una interpretación de las normas legales que permitan su plena protección. De allí que, ante la disyuntiva de aplicar las normas del sistema que tienen por finalidad la reparación de los daños o no hacerlo, deba elegirse la vía que más proteja aquellos aspectos que hemos considerado fundamentales de la persona ${ }^{55}$.

Otro argumento que sirve para justificar la responsabilidad civil en este ámbito dice relación con la norma contenida en el artículo 328 del Código Civil en los siguientes términos: En el caso de dolo para obtener alimentos, serán obligados solidariamente a la restitución y a la indemnización de perjuicios todos los que han participado en el dolo. Como se ve, es el propio Código Civil el que regula un supuesto de indemnización de perjuicios que se relaciona con la obligación alimentaria. Al respecto, podría objetarse que se trata de un supuesto en que el dolo justifica la aplicación de las reglas de responsabilidad, sin embargo, no puede desconocerse que el legislador no excluyó de manera absoluta las normas de responsabilidad de los alimentos y, como veremos en el siguiente apartado, se pueden imaginar otros supuesto de dolo en la fijación de alimentos a los que habría que aplicarles la misma ratio.

A mayor abundamiento, el Código Civil regula supuestos de alimentos entre personas que no tienen vínculos familiares entre sí (artículo 321). En ese caso no se alcanza a ver la razón por la que no pudiese utilizarse la acción de perjuicios por los daños que ocasione el incumplimiento de esta obligación. Por lo anterior, si se quisiese excluir

52 TAPIA, 2014, p. 360.

53 A propósito de la responsabilidad por el no reconocimiento del hijo, Pizarro se ha mostrado a favor de otorgar una indemnización por falta de alimentos en concepto de "pérdida de la chance". PIZARro, 2014, p. 289 y ss.

${ }^{54}$ El derecho de alimentos aparece recogido en Convención de Nueva York de 20 de junio de 1956 en los siguientes términos: son de orden público internacional las disposiciones que establecen el deber de prestar alimentos, su cuantía, reducción y aumentos, la oportunidad en que se deben y la forma de su pago, así como las que probíben renunciar y ceder ese derecho.

${ }^{55}$ Del derecho de alimentos como derecho humano puede verse en extenso: SCHMIDT, 2008; y GrEEVEN, 2018. 
la utilización de la acción de perjuicios entre familiares, la única vía para hacerlo sería anteponiendo un eventual interés del grupo familiar por sobre el individuo. Como ya se analizó, esa perspectiva está siendo superada en el derecho familiar contemporáneo.

Por último, conviene tener presente que en el derecho comparado la indemnización por los daños ocasionados por el incumplimiento de la obligación alimentaria prácticamente no es discutida ${ }^{56}$. En conclusión, no se observa ninguna razón atendible para oponerse a la reparación de los daños derivados de la violación de esta obligación. Habiendo llegado a este punto solo nos queda revisar, si del análisis de la forma específica de incumplimiento de la obligación alimentaria que tiene por objeto este trabajo (infracción al deber de transparencia patrimonial), pueden extraerse otras razones que apoyen la utilización de la institución de la responsabilidad civil en este ámbito.

2.b) La responsabilidad civil por el incumplimiento de la obligación alimentaria derivada de la infracción del deber de transparencia patrimonial

Cuando pensamos en los argumentos que pueden apoyar la utilización de la acción de perjuicios en el ámbito específico de la transgresión del deber de transparencia patrimonial, son dos los que se nos vienen a la mente: i) la interpretación analógica que se puede hacer de la regla contenida en el artículo 328 del Código Civil; y ii) el hecho de que la acción de perjuicios es la única herramienta que permite garantizar la indemnidad del alimentario en la hipótesis que aquí tratamos.

Respecto del primer argumento, ya hemos visto cómo el artículo 328 del Código Civil regula un supuesto de dolo para obtener alimentos, dándole una acción de perjuicios al defraudado contra todos los que han participado en el dolo. Pues bien, aun cuando podría sostenerse que se trata de una norma especial y que, por lo mismo, no serviría para apoyar (en términos generales) la acción indemnizatoria por el incumplimiento de la obligación alimentaria, no podrá negarse que la razón de su especialidad es la concurrencia de dolo en la fijación fraudulenta de alimentos. Si se acepta lo anterior, y se repara en el hecho de que la transgresión del deber de transparencia patrimonial adopta una forma dolosa, resultará razonable aceptar la procedencia de una indemnización que repare los daños que se conecten causalmente con la infracción del deber de transparencia patrimonial.

Respecto del segundo argumento referido, debe recordarse que una de las principales hipótesis de daño que tiene por objeto este trabajo consistente en la diferencia que media entre la pensión que injustamente se fijó y la que se debió haber fijado en la sentencia de alimentos, multiplicado por el tiempo que transcurra hasta que se descubra la verdadera situación patrimonial del alimentante y se adecuen los alimentos.

56 En Argentina, la falta de asistencia familiar es merecedora de sanción penal aparejada de multa e indemnizaciones civiles: GHERsi, 2011, pp. 40-42; FAMÁ, 2014, p. 6. En países con sólida seguridad social como España, la existencia de fondos de garantía del pago de alimentos pueden explicar la falta de desarrollo de la hipótesis de responsabilidad, pero en términos teóricos no se ven inconvenientes para que proceda. De este punto puede verse: SAAVEDRA, 2019, p. 62. 
Si se toma en consideración que los efectos de una eventual sentencia de adecuación de alimentos ${ }^{57}$ solo corrigen hacia el futuro la diferencia del monto de la pensión que constituye el daño, y que la Corte Suprema considera que no procede el recurso de revisión contra sentencias que fijen alimentos, se entenderá que la vía de la acción de perjuicios es el único mecanismo de que dispone el ordenamiento jurídico chileno para dejar indemne al alimentario en la hipótesis que aquí tratamos.

Debido al carácter fundamental de derecho de alimentos, nos parece que el recién expuesto es un poderoso argumento para justificar la utilización de la responsabilidad para reparar los daños que se deriven de la infracción al deber de transparencia patrimonial. Pensamos que los dos argumentos expuestos en este apartado, junto con los otros que se han esgrimido para apoyar la procedencia de la responsabilidad civil en el ámbito de las relaciones de familia y el ámbito más restringido de la obligación de alimentos, justifican suficientemente la procedencia de la acción de perjuicios como una vía idónea para reparar los daños que se puedan vincular con la transgresión del deber de transparencia patrimonial.

\section{2.b.1) Requisitos de la acción de perjuicios I: el problema del régimen aplicable}

Cuando nos preguntamos por los requisitos de la acción de perjuicios, el primer problema que hay que despejar, en aquellos ordenamientos (como el chileno) que regulan de forma diferenciada el régimen contractual y el extracontractual, es el del régimen aplicable. Como la hipótesis que aquí tratamos se basa en el incumplimiento de una obligación legal, en línea de principio se debería aplicar el régimen extracontractual en tanto que, salvo el caso de los alimentos entre cónyuges y de los que debe el donatario (art. 321 CC.), no es discutible el carácter extracontractual de la relación entre alimentario y alimentante ${ }^{58}$.

Si se estima que la relación es contractual y que la obligación legal de alimentos integra el contrato, debería aplicarse el régimen contractual. Sin embargo, si se tiene presente que el incumplimiento del deber de transparencia patrimonial está tipificado penalmente ${ }^{59}$, y que el derecho chileno reconoce la posibilidad de optar por la acción extracontractual en casos en que la conducta sea un delito penal ${ }^{60}$, habrá que aceptar que la acción delictual estará a disposición del alimentante en todos los casos.

${ }^{57}$ Recuérdese que no en todos los casos el demandante seguirá siendo alimentario al momento de la demanda de daños.

${ }^{58}$ En el problema del régimen aplicable a los daños derivados del incumplimiento de una obligación legal: Barros, 2006, pp. 1067 y ss. Específicamente en el ámbito del incumplimiento de deberes procesales se pronuncian por el régimen extracontractual: CACHón, 2006, pp. 18-20; CACHón y Picó, 2008, pp. 49-50; Picó, 2013, p. 131.

${ }^{59} \mathrm{La}$ conducta está prescrita en art. 5 Ley $\mathrm{N}^{\circ}$ 14.908. Una aplicación reciente del tipo penal en Juzgado de Garantía de Cauquenes, 02.08.2019, rit 667-2018.

${ }^{60}$ Por todos: Alessandri, 1943, pp. 84 y 91; y Barros, 2006, p. 1059. 
No obstante lo referido, para sortear los inevitables problemas teóricos que produce la dualidad de regímenes, si se decide interponer una acción contractual sería recomendable interponer una acción extracontractual en subsidio.

2.b.2) Requisitos de la acción de perjuicios II: la conducta antijurídica y el supuesto dañoso

Aunque no podemos realizar aquí un análisis exhaustivo de cada uno de los requisitos de la acción de perjuicios, en lo que sigue realizaremos algunas observaciones acerca de las conductas proscritas y de las condiciones fácticas que se deben dar para que el incumplimiento de la obligación de transparencia patrimonial genere un daño indemnizable. Ello se hace necesario a efectos de perfilar con mayor precisión el supuesto de hecho de la acción de perjuicios.

Respecto de las conductas proscritas, para que se configure el supuesto que venimos dibujando (infracción al deber de transparencia patrimonial), basta con que se mienta u omita información al realizar la declaración patrimonial. La antijuridicidad en este supuesto está fuera de toda discusión, en tanto que, incluso, ha sido tipificada penalmene. En efecto, en una reciente resolución que tuvo la oportunidad de analizar las condiciones para la aplicación del tipo penal contenido en esta regulación, consideró que se trata de un delito de peligro abstracto, toda vez que (...) la conducta castigada se estima peligrosa como tal, sin exigirse que en el caso concreto se haya producido un resultado de puesta en peligro efectivo ${ }^{61}$.

Sin embargo, desde el punto de vista civil, puede entenderse que otras conductas suponen una infracción al deber de transparencia. En efecto, como ya se analizó en este escrito, no tendría sentido que luego de la declaración patrimonial, el alimentante hiciera actos que tornaran inoficiosa la sentencia. De ahí que, basados en el principio de coherencia, se puede sostener que también actuará antijurídicamente a efectos de la acción de perjuicios el demandado que, habiendo declarado conforme a la realidad de su patrimonio, enajene los bienes con los que debía cumplir la totalidad o parte de su obligación alimenticia ${ }^{62}$.

En lo que dice relación con el supuesto dañoso, debe tenerse muy presente que el solo hecho de que se fije una pensión alimenticia por debajo de lo que se debió haber fijado, no constituye un daño indemnizable. Lo anterior, porque aún en el supuesto descrito, se pueden dar dos situaciones diferenciables desde el punto de vista del alimentario.

En efecto, una primera situación supone la ausencia de un daño reparable, a pesar de que no haya duda acerca del incumplimiento del deber de transparencia patrimonial. Pensamos en el supuesto en que la totalidad o parte de los alimentos sean cubiertos por el padre que ya aporta, los alimentantes subsidiarios contemplados por el artículo 326

\footnotetext{
${ }^{61}$ Juzgado de Garantía de Cauquenes, 02.08.2019, rit 667-2018.

${ }^{62}$ Referencia al apartado tratamiento del deber de coherencia.
} 
CC., o un tercero ajeno (piénsese, p. e., en la nueva pareja del padre que sí aporta). En estos casos, tomando en consideración que los alimentos han sido efectivamente provistos al alimentario, no puede propiamente decirse que ha sufrido un daño y, por lo mismo, nada podrá reclamar a este título.

Si la totalidad o parte de los alimentos que le corresponde pagar a uno de los alimentantes es asumida por una tercera persona, se estará pagando una deuda ajena. Como se sabe, las reglas del pago prescriben que el que paga por otro tiene acción para cobrar lo pagado según el pago se haya hecho con consentimiento, sin conocimiento, o en contra de la voluntad del obligado ${ }^{63}$.

La segunda situación que puede darse, sí conlleva daños indemnizables. Se trata del caso en que la totalidad o parte de los alimentos que se le deban al alimentario, no sean cubiertos por ninguna otra persona. En este supuesto, y por el tiempo que no se tengan esos alimentos, el alimentario verá lesionado su legítimo interés a recibir ciertos bienes que, a su vez, le supondrán perjuicios que deberán ser indemnizados según las reglas generales del derecho que regula los daños.

Por otra parte, cuando estemos en la hipótesis de fijación fraudulenta del monto de la pensión alimenticia, ya que el alimentario dispondrá de la acción de adecuación de alimentos y de la acción de perjuicios, es posible preguntarse si estas deberán ejercitarse conjuntamente. En nuestra opinión, estas acciones no deberán necesariamente interponerse emparejadas porque se trata de acciones concurrentes que persiguen distintas finalidades; y, además, porque puede darse la situación de que persistan daños indemnizables aún cuando ya no se tenga la calidad de alimentario. Ahora bien, siempre que el demandante conserve su calidad de alimentario y se entienda que la competencia para fallar la acción de perjuicios es del juez civil ${ }^{64}$, sería recomendable que primero se obtuviese el aumento de los alimentos. Y es que, en la práctica, una acción por daños a la que no se le acompañe como antecedente una sentencia de familia que haya aumentado los alimentos, tendrá muy pocas posibilidades de prosperar.

Cuando estamos en la hipótesis de infracción al deber de coherencia (se declaran bienes y luego se enajenan o gravan, haciendo inoficiosa la sentencia) ${ }^{65}$, la pregunta por la forma de ejercicio de las acciones ya no vinculará a la acción indemnizatoria con la acción de adecuación, sino con la acción pauliana de familia. Por cierto que en este último supuesto, ambas acciones se podrán ejercer conjuntamente pero, para ajustar los efectos de la acción de perjuicios, habrá que tener en consideración el resultado de la acción pauliana. Como se comprenderá fácilmente, son diferentes los daños indemnizables

${ }^{63}$ Debe considerarse aquí, las normas de reembolso contempladas en los artículos 240 y 241 del Código Civil.

${ }^{64}$ Aunque no podemos extendernos en este punto por razones de espacio, nos parece que existen buenos argumentos para defender la competencia de los tribunales de familiar para fallar la acción civil. Esperamos volver a este punto en un próximo trabajo.

${ }^{65}$ Piénsese, p. e., en el caso mencionado en nota 34, en que se estableció un usufructo de una casa que luego fue enajenada en el período referido. Un caso de este tipo: Tribunal de Familia de Ovalle, 18.04.2011, rol C-631-2010; Revocada por Corte de Apelaciones de La Serena, 05.08.2011, rol 63-2011. 
si la acción pauliana no tiene éxito; a lo que se producirán si, por el contrario, prospera, se reintegran los bienes al patrimonio del alimentante y se puede ejecutar la sentecia de alimentos.

Para finalizar, simplemente queremos hacer presente que la propuesta que aquí hacemos deja pendiente el análisis particular de los tipos de daños que serían indemnizables en cada hipótesis. Pero, además, nos fuerza a afrontar problemas que tienen que ver, entre otros aspectos, con la prescripción de la acción indemnizatoria, con la identificación de los hechos que se deben acreditar (p. e., efectividad del patrimonio que realmente se tenía cuando se hizo la declaración), o con el tribunal competente. Ya habrá tiempo para analizar cada uno de esos desafíos, pero no tenemos dudas de que todos esos problemas deberán sortearse con relativa celeridad, si se comparte la idea de que el principio de indemnidad debe ser especialmente garantizado cuando se trata de alimentos.

\section{Conclusiones}

1. En el ordenamiento jurídico chileno se introdujo una particular disposición normativa (art. $5^{\circ}$ inciso primero de la Ley $\mathrm{N}^{\circ}$ 14.908) que obliga al alimentante a transparentar su capacidad económica, mediante la demostración documental o una declaración jurada, en la audiencia preparatoria del juicio de alimentos.

2. Una interpretación sistemática de la referida norma con los principios generales del proceso (p. e., buena fe) y otras normas específicas (p. e., las normas que regulan las declaraciones juradas), nos permite afirmar la existencia de deberes (veracidad, completitud y coherencia) que el alimentante deberá observar durante todo el proceso de alimentos.

3. Si el alimentante infringe la obligación o los deberes referidos, y esa infracción tiene como consecuencia la fijación injusta de los alimentos o una sentencia justa que luego deviene en inoficiosa, debe responder civilmente de los daños que se vinculen causalmente con su conducta antijurídica.

4. En caso de que la disminución de los alimentos necesarios no sea suplida por una tercera persona, el alimentante deberá resarcir la diferencia entre los alimentos efectivamente fijados y los que se debieron haber fijado si no se hubiese producido la falsedad, multiplicada por el período de tiempo que va desde la dictación de la sentencia injusta y la sentencia que adecue los alimentos.

5. En caso de que la conducta posterior a la declaración del alimentante torne la sentencia en inoficiosa, infringiendo así el deber de coherencia, el alimentario contará a su disposición con la acción pauliana y con la acción de perjuicios, las que se podrán ejercer conjuntamente ajustando esta última en consideración al resultado de la primera. 


\section{BIBLIOGRAFÍA}

Aguirrézaval G., Maite, 2015: "El deber de colaboración y la conducta procesal de las partes", Revista chilena de derecho privado de derecho de familia, $\mathrm{N}^{\circ} 25$, pp. 303-312.

Alessandri R., Arturo, 1943: De la responsabilidad extracontractual en el derecho civil chileno. Santiago, Imprenta Universitaria.

Álvarez E., Rommy, 2019: Daños en las relaciones familiares y el derecho a la identidad en la filiación. Santiago, Editorial Thomson Reuters.

Alvear H., Cristián, 2015: "La declaración de patrimonio del artículo 5 de la Ley No 14.908. Una institución subvalorada”, Revista de derecho de familia, $\mathrm{N}^{\circ}$ 5, vol. 1, pp. 37-46.

BARrientos G., Javier, 2015: El código de la familia: normativa y jurisprudencia sistematizada, concordada y comentada de derecho de familia (4ª edición), Santiago, Editorial Thomson Reuters.

Barros B., Enrique, 2006: Tratado de responsabilidad extracontractual, Santiago, Editorial Jurídica de Chile.

Cachón C., Manuel, 2006: "La buena fe en el proceso civil”, Revista de derecho procesal, № 1-2 febrero, pp. 7-44.

Cachón C, Manuel y Picó, Joan, 2008: Ejecución civil: Problemas actuales, Barcelona, Editorial Atelier Libros Jurídicos.

Carretta M., Francisco, 2008: "Deberes procesales de las partes en el proceso civil chileno: Referencia a la buena fe procesal y al deber de coherencia”, Revista de Derecho (Valdivia), $\mathrm{N}^{\circ}$ 1, vol. XXI, pp. 101-127.

Condorelli, Epifanio, 1986: Del abuso y de la mala fe dentro del proceso, Buenos Aires, Editorial Abeledo Perrot.

Davis E., Hernando, 1997: Teoría general del proceso. Aplicable a toda clase de procesos ( $3^{a}$ edición), Buenos Aires, Editorial Universidad.

Dutro A., Ricardo, 2007: Daños ocasionados en las relaciones de familia, Buenos Aires, Editorial Hammurabi,

FAmÁ, María Victoria, 2014: “Jurisprudencia española. Daños y perjuicios en el derecho de familia”, Revista de derecho de familia: doctrina, jurisprudencia, legislación, $\mathrm{N}^{\circ}$ 65, pp. 2-24.

Ferrer I RibA, Josep, 2001: "Relaciones familiares y límites al derecho de daños”, InDret: Revista para el análisis del derecho, $\mathrm{N}^{\circ} 4$, octubre, s/p.

Ferrer S., Antonio, 1996: "La estafa procesal", Anuario de derecho penal y ciencias penales. Sección Doctrinal, pp. 5-12.

Garrido C., Carlos, 2014: Derecho de Alimentos. Análisis actualizado y formularios, Santiago, Editorial Metropolitana.

Ghersi, Carlos, 2011: "Daños derivados de las relaciones internas del derecho de familia", Revista de responsabilidad civil y seguros: publicación mensual de doctrina, jurisprudencia y legislación, $\mathrm{N}^{\circ} 10$, año 13 , pp. 35-54.

Goldschmidt, James, 1936: Derecho procesal civil, Barcelona, Editorial Labor S.A.

GonzÁlez C., María, 2012: "La carga dinámica de la prueba", Revista de derecho procesal, № 22, pp. 363-396.

González C., María, 2013: La carga dinámica de la prueba y sus límites, Chile, Editorial Thomson Reuters.

Gorigoitía A., Felipe, 2008, "La buena fe en el proceso civil chileno", Revista Nomos, Universidad de Viña del Mar, $\mathrm{N}^{\circ}$ 2, pp. 133-159.

Greeven B., Nell, 2018, Derecho de alimentos como derecho bumano y apremios para obtener el cumplimiento. Santiago, Editorial Librotecnia. 
Hernández B., Héctor, 2010: "La estafa triangular en el derecho penal chileno, en especial la estafa procesal”, Revista de derecho universidad austral de Chile, No 1, vol. XXIII, julio, pp. 201-231.

Hernández P., Gabriel, 2016: "Las consecuencias de la infracción de deberes matrimoniales no dan lugar a indemnización”, Revista chilena de derecho privado, N²7, pp. 95-139.

Howard, Walter, 2016: "Panorama jurisprudencial de la responsabilidad en el derecho de familia", Revista de derecho de la Universidad de Montevideo, No 30, pp. 171-188.

Hunter A., Iván, 2007: "Poderes del juez civil: algunas consideraciones a propósito del juez de familia”, Revista de Derecho, No 1, vol. 20, pp. 205-229.

Hunter A., Iván, 2008: "No hay buena fe sin interés: La buena fe procesal y los deberes de veracidad, completitud y colaboración”, Revista de Derecho, № 2, vol. 21, pp. 151-182.

Instituto Nacional de Estadísticas, 2016: Informe anual de justicia, año 2015, Santiago, Instituto Nacional de Estadísticas.

Instituto Nacional de Estadísticas, 2015: Informe anual de justicia, año 2014, Santiago, Instituto Nacional de Estadísticas.

Instituto Nacional de Estadísticas, 2014: Informe anual de justicia, año 2013, Santiago, Instituto Nacional de Estadísticas.

Lepín M., Cristián, 2014: "Incumplimiento de la obligación alimenticia", Revista la semana jurídica, $\mathrm{N}^{\circ} 341$, semana del 21 al 27 de mayo.

Lepín M., Cristián, 2017: Derecho familiar chileno, Santiago, Editorial Thomson Reuters.

Martín-Casals, Míquel y Ribot, Jordi, 2011: "Daños en derecho de familia: un paso adelante, dos atrás”, Anuario de derecho civil, $\mathrm{N}^{\circ} 2$, volumen 64, pp. 503-560.

Maturana M., Cristián y Mosquera R., Mario, 2010: Los recursos procesales, Santiago, Editorial Jurídica de Chile.

Medina, Graciela, 2015: "Daños en el derecho de familia en el código civil y comercial unificado", Revista de derecho de familia y sucesiones, $\mathrm{N}^{\circ}$ 5, septiembre, pp. 15-46.

Meneses P., Claudio, 2008: “Aspectos procesales de la Ley No 20.152; que incorpora modificaciones relativas a los juicios de alimentos”, Revista de estudios de la justicia, No 10, pp. 221- 249.

Montero A., Juan, 2006: "Sobre el mito autoritario de la buena fe procesal”, en Juan Montero A. (coord.), Proceso civil e ideología: Un prefacio, una sentencia, dos cartas y quince ensayos, Valencia, Editorial Tirant lo Blanch.

Nieva F., Jordi, Ferrer B., Jordi y Giannini, Leando, 2019: Contra la carga de la prueba, Madrid, Editorial Marcial Pons.

NúÑez A., Rene y CoRTÉs R., Mauricio, 2012: Derecho procesal de familia. La primera reforma procesal civil en Chile, Santiago, Editorial Thomson Reuters.

Patti, Salvatore, 1984: Famiglia e responsabilidad civile, Milano, Dott A. Giuffre Editore.

Padilla P., Ricardo, 2013: "Por una correcta aplicación de la doctrina de los actos propios", Revista Chilena de Derecho Privado, No 20 (julio), pp. 135-183.

Pérez Ragone, Álvaro y Silva Álvarez, Oscar, 2009: "El imperativo de transparencia patrimonial del deudor como requisito funcional para una ejecución civil eficiente", Revista Ius et Praxis (Talca), vol. 15, $\mathrm{N}^{\circ} 2$, pp. 79-115.

Picó I Junoy, Joan, 2013: El principio de la buena fe procesal, Barcelona, Editorial J.M. Bosch Editor. Pizarro W., Carlos, 2014: "Responsabilidad civil por no reconocimiento voluntario del hijo de filiación extramatrimonial”, en Cristián Lepin M. (dir.) y David Vargas A. (coord.), Responsabilidad civil y familia, Santiago, Editorial Thomson Reuters.

Ramos P., René, 2010: Derecho de familia (7ª edición), tomo II, Santiago, Editorial Jurídica de Chile.

Roca T., Encarna, 1999: Familia y cambio social (De la "casa" a la persona), Madrid, Editorial Cuadernos Civitas. 
Roca T., Encarna, 2000, "La responsabilidad civil en el derecho de familia. Venturas y desventuras de cónyuges, padres e hijos en el mundo de la responsabilidad civil", Perfiles de la responsabilidad civil en el nuevo milenio, Juan Antonio Moreno Martínez (coord.), Madrid, Editorial Dykinson.

Schmidt H., Claudia, 2008: Del derecho alimentario familiar en la filiación, Santiago, Editorial Puntolex.

SAAVEDRA S., Geraldine, 2019: Incumplimiento de la pensión de alimentos. El arresto y otras sanciones, Chile, Rubicón Editores.

SÁnCHez, G., Carlos, 2019: El juez de familia y sus facultades, Chile, Rubicón Editores.

TAPiA R., Mauricio, 2014, "Principios, reglas y sanciones del derecho de las familias", en Lepin M., Cristián (dir.) y Vargas A., David (coord.), Responsabilidad civil y familia, Santiago, Thomson Reuters.

TAPIA R., Mauricio, 2018: Divorcio y responsabilidad civil, Chile, Rubicón Editores.

TANZI, Silvia Y. y PAPIllú, Juan M., 2011: "Daños y perjuicios derivados del divorcio (Doctrina y jurisprudencia en Argentina)", Revista Chilena de Derecho Privado, No 16, julio, pp. 135-161.

Turner, Susan, 2017: "El daño en la jurisprudencia nacional sobre responsabilidad civil entre cónyuges”, en Corral, Hernán y Manterola, Pablo (editores), Estudios de derecho civil XII, XIV Jornadas nacionales de derecho civil, 2016, Santiago, Thomson Reuters, pp. 557-665.

Valenzuela, Pepa, 2019: Un tormento llamado pensión alimenticia, Recuperado el 17.12.2019, de TheClinic.cl: HTTPS://WWW.THECLINIC.CL/2019/06/13/UN-TORMENTO -LLAMADO-PENSION-ALIMENTICIA/

Varas Braun, Juan Andrés, 2016: “Corazón roto: ¿daño indemnizable?”, en Estudios de derecho civil XI, XIII Jornadas nacionales de derecho civil, 2015, Santiago, Thomson Reuters, pp. 139-148.

VArgas A., David, 2015: "Del resarcimiento en Chile de los daños causados en el matrimonio", Revista Ius et Praxis Universidad de Talca, No 21, año 21, pp. 57-100.

Vivanco L., Pablo, 2018: Responsabilidad civil en el ámbito del derecho de familia, Santiago, Editorial Thomson Reuters.

\section{Normas jurídicas citadas}

Ley N 14.908 , Sobre Abandono de Familia y Pago de Pensiones Alimenticias, publicada el 30 de mayo de 2000.

LEy N ${ }^{\circ}$ 19.968, Crea los Tribunales de Familia, publicada el 30 de agosto de 2004.

\section{Jurisprudencia citada}

Corte de Apelaciones de Chillán, sentencia de 24 de mayo de 2015, rol 9-2015.

Corte de Apelaciones de Concepción, sentencia de 08 de septiembre de 2011, rol 444-2011.

Corte de Apelaciones de Concepción, sentencia de 30 de junio de 2016, rol 297-2016.

Corte de Apelaciones de La Serena, sentencia de 12 de agosto de 2015, rol 111-2015.

Corte de Apelaciones de la Serena, sentencia de 05 de agosto de 2011, rol 63-2011.

Corte de Apelaciones de Valparaíso, sentencia de 08 de septiembre de 2011, rol 247-2015.

Corte de Apelaciones de Talca, sentencia de 30 de agosto de 2012, rol 133-2012.

Corte Suprema, sentencia de 10 de agosto de 2011, rol 7322-2011.

Corte Suprema, sentencia de 15 de diciembre 12 de 2014, rol 18924-2014. 
Corte Suprema, sentencia de 16 de agosto de 2016, rol 44994-2016.

Corte Suprema, sentencia de 30 de diciembre de 2014, rol 10622-2014.

Juzgado de Garantía de Cauquenes, sentencia de 02 de agosto de 2019, rit 667-2018.

Tribunal de Familia de Ovalle, sentencia de 18 de abril de 2011, rol C-631-2010. 
